\title{
TRADISI TURUN-TEMURUN PEMBUATAN BATIK MASYARAKAT KAMPOENG BATIK LAWEYAN SURAKARTA (SEBUAH TINJAUAN BUDAYA)
}

\author{
Prasetyo Adi Wisnu Wibowo \\ Program Studi Sastra Daerah Fakultas Ilmu Budaya Universitas Sebelas Maret \\ E-mail: prasetyoadiwisnuwibowo@yahoo.co.id
}

\begin{abstract}
Abstrak
Batik, yang sejak ratusan tahun silam dikenal sebagai jarit 'kain panjang' untuk kaum bangsawan Indonesia (Jawa), kini telah meluas dalam produksi maupun arti fungsi pemakaiannya. Dalam tulisan ini akan dipaparkan bagaimana proses pembuatan batik di kampung Laweyan. Bentuk penelitian ini adalah deskriptif kualitatif. Sumber data dalam penelitian ini adalah prosesi membatik di kampung batik Laweyan, informan perajin batik di kampung batik Laweyan, serta naskah lama. Teknik pengumpulan data dengan menggunakan teknik catat, rekam, dan wawancara mendalam. Teknik analisis data menggunakan langkah-langkah reduksi data, sajian data, dan penarikan kesimpulan. Proses pembatikan suatu kain memerlukan tahapan-tahapan khusus yang dimulai dari pemilihan kain mori yang baik, membuat pola dengan ceceg, nembok sampai proses terakhir yaitu mababar. Untuk membuat satu lembar kain dengan motif batik memerlukan alat-alat khusus, antara lain wajan, gawangan, canthing, bandhul, dan lilin atau malam. Banyak sekali jenis-jenis motif kain batik antara lain sidamukti, sidaraja, parangrusak dan sebagainya. Pada jaman dahulu seorang wanita Jawa diharuskan untuk mampu membatik. Adapun kampung yang terkenal sebagai sentra industri kerajinan batik adalah kampung Laweyan di Surakarta dan telah ada sejak zaman kerajaan Pajang.
\end{abstract}

Kata-kata Kunci: Laweyan, batik, tradisi turun-temurun.

\section{THE HEREDITARY TRADITION OF MAKING BATIK COMMUNITY OF KAMPOENG BATIK LAWEYAN SURAKARTA (A CULTURAL REVIEW)}

\author{
Prasetyo Adi Wisnu Wibowo
}

\author{
Regional Literature Study Program, Faculty of Cultural Sciences, Sebelas Maret University \\ E-mail: prasetyoadiwisnuwibowo@yahoo.co.id
}

\begin{abstract}

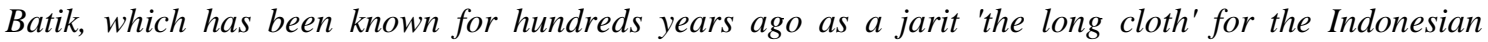
(Javanese) nobility, has now expanded in production and the meaning of its usage function. This research will be explained of the process of making batik in Laweyan village. The type of this research is qualitative descriptive. The data sources in this research were batik processions in Kampoeng Batik Laweyan, the informants of batik artisans in Laweyan batik village, and the old manuscripts. The techniques collecting data uses content analysis, recording, and in-depth interviews. The techniques of data analysis use steps of data reduction, data presentation, and conclusion. The process of turning a cloth requires special steps starting from the selection of a good cloth, making a pattern with ceceg, wallowing until the last processthat called mababar. To make one sheet of cloth with batik motifs requires special tools, including frying pans, gawangan, canthing, bandhul, and candles. Lots of types of batik cloth motifs, among others, Sidamukti, Sidaraja, Parangrusak and so on. In ancient times a Javanese woman was required to be able to make batik. The village which is famous as the center of batik handicraft industry is Laweyan village in Surakarta and has been around since the kingdom of Pajang.
\end{abstract}

Key Words: Laweyan, batik, hereditary tradition. 


\section{PENDAHULUAN}

Tradisi pembuatan batik sudah ada sejak ratusan tahun lalu. Kain batik pada jaman dahulu hanya merupakan kain panjang yang khusus dipakai oleh kaum bangsawan (istana). Masyarakat di luar istana jarang sekali memakai sinjang bathik 'kain panjang dengan motif batik'. Seni pembuatan batik pada jaman dahulu berawal dari dalam karaton. Pada jaman dahulu bahan pakaian yang dibuat batik hanya sebatas pada pembuatan sinjang atau jarit 'kain panjang' dengan motif-motif yang sederhana. Lama-lama batik meluas bentuk dan fungsinya. Cakrik 'motif batik' semakin bertambah dan fungsi batik tidak hanya digunakan sebagai sinjang, tetapi ada yang dibuat untuk kemeja panjang, tas, dan sebagainya.

Perdagangan batik akhirnya meluas di seluruh pulau Jawa. Sentra industri pembuatan batik yang terkenal ada di Surakarta, Yogyakarta, Pekalongan, dan wilayah Banyumas yang meliputi Purwareja(Tlampok) Sukaraja, Purbalingga dan Purwakerta. Para juragan bathik 'pengusaha bathik' ada yang berasal dari orang Tionghoa, Jawa, maupun keturunan Arab.

Laweyan adalah kampung batik di kota Surakarta. Di dalamnya memiliki keunikan-keunikan yang perlu dikuak sebagai khazanah budaya. Keunikan tersebut di antaranya dapat dilihat dari tradisi masyarakat Laweyan yang bermata pencaharian dari perdagangan dan pembuatan kain batik. Selain itu dapat dilihat dari segi arsitekturnya. Arsitektur Laweyan unik-unik, tampak dari tembok-tembok yang menjulang tinggi, rumah-rumah berukuran besar. Hal ini dikarenakan ekonomi masyarakat Laweyan saat itu mengalami kemajuan pesat. Kemajuan dan ketelatenan itu berkat keuletan Kyai Haji Samanhudi. Masa kejayaan Laweyan dari perdagangan batik terus berkesinambungan sejak abad 15 sampai sekarang.

Dalam tulisan ini akan dipaparkan bagaimana proses pembuatan batik di kampung Laweyan. Proses pembuatan batik di Laweyan merupakan tradisi yang sudah turun-temurun sejak zaman Kerajaan Pajang tahun 1546 M yang pada waktu itu dimulai dari perdagangan lawe di daerah Nglaweyan atau Laweyan.

Batik yang sejak beberapa ratus tahun silam hanya dikenal sebagai jarit 'kain panjang' untuk kaum bangsawan Indonesia (Jawa), kini telah meluas dalam arti pemakai maupun produksinya. Bahkan setelah perang kemerdekaan selesai yaitu tahun 1950, batik bukan lagi mutlak dipakai sebagai kain panjang saja, tetapi juga merupakan kain 
sandang yang serba guna bagi bangsa Indonesia. Batik yang beraneka ragam dan serba guna ini sekarang telah dikenal di seluruh dunia sebagai hasil seni dan kerajinan bangsa Indonesia yang khas berkepribadian sendiri (Institut Teknologi dan Pendidian, 1960: 2) Di bawah ini akan diuraikan sejarah perkembangan pembuatan batik.

Tahun 1914 terjadi perang besar di Eropa. Pada waktu itu bangsa Tionghoa yang mengetahui keuntungan besar dari perdagangan batik, kemudian mulai mendirikan pabrik-pabrik pembuatan batik. Pada umumnya bangsa Tionghoa memiliki modal yang kuat, sehingga mereka mampu membayar pekerja batik. Batik yang dihasilkan oleh orang-orang Tionghoa ini akhirnya bisa meniru pola-pola buatan bangsa Eropa. Tradisi membatik tersebut pada akhirnya ditiru oleh bangsa pribumi (orang Jawa). ${ }^{1}$

Membatik merupakan pekerjaan yang memerlukan kesabaran dan konsentrasi penuh, oleh karena itu biasanya pekerjaan ini dilakukan oleh ibu rumah tangga. 2 Meskipun merupakan pekerjaan yang monoton dan dianggap pekerjaan yang mengotori tangan, namun sebagian masyarakat Jawa khususnya di Laweyan berkeyakinan bahwa seorang wanita harus bisa membatik.

1. Batik di daerah Banyumas

Perdagangan batik di karesidenan Banyumas boleh dikatakan dikuasai oleh bangsa Tionghoa. Hampir di seluruh wilayah Banyumas menjadi sentra kebudayaan batik, misalnya di Purwareja (Tlampok) Sukaraja, Purbalingga, dan Purwakerta.

Pekerjaan membatik yang dikuasai oleh orang-orang Tionghoa di Banyumas, pada akhirnya ditempatkan dan diserahkan pada orang-orang pribumi dengan berbagai macam perjanjian, misalnya juragan bathik menyediakan peralatan, juragan hanya menerima bahan jadi saja. Sehingga pekerjaan membatik sudah diborong oleh pekerja yang berasal dari orang-orang pribumi. Pemborong pekerjaan membatik, disebut dengan istilah anèmêr. Bekerja melalui anèmêr dirasakan lebih enak, sebab anèmêr berperan penting dalam meringankan pekerjaan.

Pekerjaan membatik pada umumnya dilakukan oleh para wanita. Pada pekerjaan yang ringan bisa juga dilakukan oleh anak-anak. Sedangkan pada pekerjaan yang berat, misalnya nyelup, nglorod, dikerjakan oleh para pria. Sistem pembayaran yang dilakukan oleh seorang juragan bathik kepada para pekerjanya, bergantung kepada sistem yang

$1 \quad$ Kajawèn: angka 55, 24 Sapar taun Je 1862. 11 Juli 1931. Taun VI, Palapuran Bathik, hal. 850.

$2 @$ @ Lampiran Kajawèn nomêr 26, 29 Juni 1938 taun III, Jagading Wanita, hal. 139, Bab nyerat (ambathik). 
diambil sejak awal. Jika ia menyerahkan pada anèmêr, maka upah pekerja diborong sekaligus oleh anèmêr. Jika tidak, maka juragan bathik akan memberi upah sesuai dengan hasil pekerjaan, bisa harian, mingguan atau bulanan. 3

Adapun ragam hias yang biasa dipakai adalah bagian-bagian tumbuhan misalnya godhong-godhongan, lung-lungan 'tiruan sulur dan dedaunan', bagian binatang, yaitu lar 'sayap burung', kepala burung, dan sebagainya.

2. Batik di daerah Surakarta (Laweyan) dan Yogyakarta (batik cakrik kina)

Hal-hal yang baku dalam hal kain batik, bisa diambil berasal dari Surakarta dan Yogyakarta. Kain batik keluaran dari kedua kota tersebut memiliki wangun atau bentuk masing-masing, yakni warna sogan lebih terang.

Kain batik keluaran kota Surakarta warna soga cenderung merah, sedangkan batik Yogyakarta serba pantas, bersih cenderung kuning terang. Oleh karena itu, untuk kain batik bermotif kawung batik Yogyakarta lebih dipilih. ${ }^{4}$

Batik di Laweyan tidak lepas dari sejarah Ki Ageng Nis sebagai tokoh besar di daerah Laweyan pada masa Kerajaan Pajang. Ketika jaman Pajang tahun 1546 M di daerah Laweyan terkenal dengan perdagangan lawe. Lawe adalah sejenis benang untuk pembuatan sebuah kain. Perdagangan lawe ini telah menjadi mata pencaharian masyarakat Laweyan. Di selatan kampung Laweyan dahulu ada bandar pelabuhan yang cukup besar untuk perdagangan lawe ini yang terkenal dengan nama Bandar Kabanaran. Lambat laun masyarakat Laweyan mengikuti keahlian orang-orang kraton dalam membuat kain batik. Puncak kejayaan Laweyan sebagai kampung batik selalu berkelanjutan dari generasi ke generasi berikutnya. Pada awal abad XX di Laweyan muncul tokoh besar yaitu seorang pengusaha batik yang bernama Kyai Haji Samanhudi. Samanhudi mendirikan Sarekat Dagang Islam sebagai sebuah organisasi perdagangan dalam rangka menyejahterakan anggotanya. Pada masa Samanhudi, perdagangan batik di Laweyan dan kota Solo sudah dimonopoli oleh orang-orang Tionghwa. Hal inilah yang akhirnya mendorong berdirinya Koperasi Batari, Koperasi PPBS, dan perkumpulan dagang lainnya di kota Solo. Puncak kejayaan Samanhudi yaitu berdirinya Sarekat Islam yang sebelumnya berupa perserikat dagang akhirnya bergerak sebagai sebuah organisasi politik. 


\section{METODE PENELITIAN}

Bentuk penelitian ini adalah penelitian kualitatif deskriptif. Penelitian kualitatif deskriptif bertujuan untuk mengungkapkan berbagai informasi kualitatif dengan pendeskripsian yang teliti dan penuh nuansa untuk menggambarkan secara cermat sifatsifat suatu hal (individu atau kelompok), keadaan, gejala atau fenomena yang lebih berharga daripada sekedar pernyataan dalam bentuk angka-angka dan tidak terbatas pada pengumpulan data melainkan meliputi analisis dan interpretasi data (Sutopo, 1996: $8-10)$

Sumber data dalam penelitian ini adalah tradisi membatik di kampung batik Laweyan, informan perajin batik di kampung batik Laweyan, serta naskah lama. Data berupa prosesi membatik, informasi dari narasumber mengenai tradisi membatik, dan informasi batik dalam naskah lama. Teknik pengumpulan data dengan menggunakan teknik catat, rekam, dan wawancara mendalam. Teknik analisis data menggunakan langkah-langkah reduksi data, sajian data, dan penarikan kesimpulan.

\section{HASIL DAN PEMBAHASAN}

\section{Alat dan bahan}

\subsection{Alat-alat Membatik}

Alat-alat untuk membatik, yaitu 1) Gawangan berupa palang pring ini disebut juga padhawangan, 2) Canthing adalah alat untuk membathik atau membuat guratanguratan gambar pada kain), ada. canting dengan satu lubang dan ada pula canting dengan dua lubang atau disebut dengan istilah canthing carat kalih, 3) Cap ada yang berbentuk segi empat, bujur sangkar, jajaran genjang atau lonjong. Motif batik yang tertera pada cap terbuat dari bahan tembaga dengan pegangan cap yang terbuat dari besi,

4) Kuas dipergunakan untuk nembok yaitu menutupi bagian-bagian yang kosong atau bagian yang hendak dicelup dengan warna lain. Nembok pada kain batik ini disebut dengan istilah noled, 5) Bandhul. Kain agar mudah dibatik (supaya kencang dan tidak kendor) dipergunakan bandhul. Bandhul dapat menggunakan batu kali, batu bata, atau kaleng kecil yang telah diisi dengan campuran semen, 6) Malam 'lilin', 7) Kompor kecil serta wajan.

\subsection{Bahan dan Obat Batik}


Bahan utama yang digunakan dalam pekerjaan membatik adalah mori 'kain'. Mori yang akan digunakan harus dipilih yang terbaik, untuk selanjutnya kain mori yang baik akan diolah. Bahan lain berupa malam 'lilin'.

Obat-obatan kimia untuk pekerjaan membatik di antaranya soga dan naptol. Bathikan lugu menggunakan malam 'lilin' yang ditumpahkan dari canthing ke kain putih. Wujud demikian disebut bathikan lugu yang belum terlihat bagian mana yang akan menjadi wêdêlan, sogan, atau warna putih.

Semua kain batik jika sebelum diwedel masih berwarna putih, berarti nanti warnanya akan berubah menjadi hitam. Semua tembokan nantinya akan berwarna putih (berasal dari warna putih tembokan). Semua cêcêg nantinya berwarna putih (berasal dari putihnya biron). Semua sawut atau garit-garit dan bathikan lain warnanya sama dengan soga. 5 Adapun bahan naptol adalah sejenis bahan kimia yang dipergunakan untuk mewarna kain batik.

\section{Proses Pembuatan Batik}

Proses pembuatan satu kain batik yang penuh dengan cakrik 'motif' dan warna yang indah memerlukan waktu serta langkah-langkah yang sangat panjang, yaitu mulai nggirah 'mencuci mori', ngethel, nyorek 'memberi gambaran pola pada kain', ngiseni, nembok, nyelup sampai mbabar atau nglorod lilin pada kain. Adapun uraian lengkap proses pengerjaan batik sampai menjadi kain yang siap dipakai adalah sebagai berikut.

\subsection{Anggirah montên 'mencuci mori'}

Pada tingkat pekerjaan yang pertama ini mula-mula kain putih perlu dihilangkan dahulu kanji aslinya (appretmasa) dengan cara merendam kain-kain putih tersebut selama semalam dalam air bersih. Kemudian pada pagi harinya kain dicuci dalam campuran air sabun dan merang. Adapun cara nggirah mori sebagai berikut.

Merebus air sampai mendidih, kemudian memasukkan sabun cuci secukupnya ditambah untingan merang 'batang padi' sampai penuh. Jika merang sudah hancur, mori yang sudah direndam air selama semalam, lalu dimasukkan ke air rebusan merang, diaduk kira-kira 25-30 menit, setelah bercampur, diangkat dan dimasukkan ke dalam wadah baru (biasanya tong). Jika kanji sudah tidak menempel pada mori, lalu dicuci dengan air biasa, baru kemudian dikanji dengan kanji yang tipis saja.

\subsection{Nganji 'menganji'}


Kain yang telah bersih dari kanji aslinya kemudian dikanji dengan kanji yang tipis saja. Setelah itu dijemur di tempat penjemuran mori. Setelah diambil dari jemuran, lalu dikeringkan dengan cara diangin-anginkan di tempat sejuk selama 1 malam agar kain mori lemas.

Adapun maksud penganjian kain putih tersebut, yaitu a. menjaga agar benangbenang pada kain putih jangan mudah bergerak lagi bila nanti kain putih akan dicap atau dibatik, b. menjaga agar lilin batik yang panas nanti jangan terus meresap ke bagian 'terusan' sehingga hasilnya kurang baik.

\subsection{Ngemplong}

Mori yang benar-benar kering setelah didiamkan satu malam, kemudian digulung dengan tatanan 5-20 lembar per gulungnya, kemudian dipacking yakni diberi tali pada bagian kiri, kanan, dan tengah. Lalu diletakkan di atas balok kayu yang kuat dan berserat halus berukuran $20 \mathrm{~cm}$ atau $25 \mathrm{~cm}$ persegi. Mori diikat menjadi 3 bagian, kemudian dikemplongi 'dipukul-pukul' dengan alat pemukul berupa gandhen dari kayu secara merata. Selanjutnya, mori yang sudah kendur karena dipukul, digulung lagi sampai kuat, dan dipukul-pukul lagi. Jika mori sudah terlihat halus, lalu digulung kencang pada kayu yang bulat untuk menghilangkan lipatan. Dengan demikian proses pembatikan atau pengecapan bisa merata. 6

Menghaluskan serta meratakan kain putih ini haruslah dikerjakan secara berulang-ulang sehingga kain putih menjadi rata dan halus. Pekerjaan mengemplong ini tidak dapat dengan cara menyeterika kain, karena meratakan secara demikian akan menyebabkan kesulitan untuk pekerjaan selanjutnya. ${ }^{7}$

\subsection{Ngêthèl montên}

Sesudah kain putih kita cuci dari kanji aslinya, maka kain putih harus kita kethel dahulu dengan minyak kacang dan soda. Pekerjaan ini sangat penting disebabkan karena: dengan kethelan yang cukup masak maka warna kain akan cukup mengkilat dan terang atau warna cat dengan mudah meresap ke dalam benang tenunan.

Bahan-bahan yang dipakai adalah a. minyak kacang atau dapat diganti dengan minyak jarak, minyak nyamplung, minyak klentheng atau minyak biji kapuk randhu, $b$.

\footnotetext{
6 @ Kajawèn: angka 90, Ju, Pn, 8 Sawal, Dal 1871. 8 Nopèmbêr 1940, taun XV, hal. 1271, Kawruh Bathik Warni-warni..

7 Departemen Perindustrian Rakyat, Batik, 1960, hal. 8.
} 
air abu merang (landha) atau dapat diganti dengan air soda abu, air abu dapur dan air coustic soda (Departemen Perindustrian Rakyat, 1960: 13) .8 Adapun bahan-bahan yang perlu dipersiapkan sebagai berikut.

1 kaleng (kira-kira 20 liter) landha mêrang ayit dicampur dengan 2 cangkir (200 cc) minyak jarak, lalu diaduk sampai bercampur. Campuran tersebut didiamkan selama satu malam. Mori kemudian dimasukkan ke dalam campuran landha dan minyak jarak kurang lebih 1 jam lamanya sambil diaduk-aduk. Selanjutnya mori dijemur.

Jika sudah kering lalu direndam lagi pada campuran landha merang dan minyak jarak, lalu diuleni dan dijemur lagi. Lama pengulenan tergantung pada hasil yang ingin dicapai, semakin lama proses pengulenan, semakin halus dan bersih kain yang dihasilkan. Terakhir mori direndam pada air landha untuk pembersihan. Jika sudah terendam benar, diuleni lagi untuk menghilangkan minyak jarak, kemudian dibilas dengan air biasa lalu direbus.

Cara merebus terlebih dahulu mencampurkan air panas dengan sabun cuci, dan direbus seperlunya, diangkat dan dimasukkan ke dalam air dingin, dibilas pertama dan dibilas lagi untuk kedua kalinya. Selanjutnya kain ditiriskan pada gawangan lalu dijemur. Kain ini merupakan kain yang sudah siap dikerjakan (dibatik atau dicap). Sebelum dibatik atau dicap, kain harus dikanji atau dipukul-pukul lagi.

Ngêthèl dengan campuran landha merang dan minyak jarak harus bersih agar soga dan celepan bisa menempel. Manfaat landha merang adalah menghilangkan kotoran pada kain maupun kanji yang menempel pada kain.

\subsection{Nyorek 'membuat pola'}

Pembuatan gambaran atau pola pada kain jaman dahulu tidak tentu di atas kertas, kadang-kadang di atas kain yang tak terpakai, ada juga yang dilakukan dengan cara langsung dibatik dengan malam 'lilin'. Selain itu, jika ada kekurangan dalam membuat pola, masih bisa menambah dengan pola lainnya karena bathikan model lama memiliki cakrik yang sama. Model ini memiliki pola baku berupa ceceg 'titik-titik', sisik 'menyerupai sisik ikan', cacah gori 'menyerupai nangka muda yang dicacah', dan sisikmelik. 9

8 Departemen Perindustrian Rakyat, Batik, 1960, hal 13.

9 Kajawèn: angka 66, Rêbo, Kliwon, 11 Jumadilakir Ehe 1868. 18 Agustus 1937, taun XII, hal. 126 
Sinjang latar pêthak umumnya dikerjakan dengan menggunakan pola. Maksud pembuatan pola mula-mula mengambil pola sinjang 'kain panjang' yang wujudnya hanya mori berisi batikan yang ditempelkan di atas mori yang akan dibatik, lalu diberi dom bundhêl 'jarum pentul' di bagian pinggir. Jadi, pola diblat langsung tetapi tetap memperhatikan agar pemasangannya tepat dan sesuai, sehingga jêjêr berada di bagian tengah. Setelah itu kain mulai dibatik.

Cara membatik kain dengan mempergunakan pola atau mola, harus dilakukan di tempat yang cukup terang agar bathikan yang dipola bisa tepat dan jelas. Apabila satu pola sudah selesai, maka pola diambil dan mori yang sudah digambar dengan pola kemudian dilipat. Bagian yang belum digambar atau dipola, digambar sesuai dengan pola yang sudah ada tadi. Demikian seterusnya, sampai mori penuh dengan gambar sesuai dengan pola. Proses pembuatan pola ini disebut juga ngengreng. 10

2.6 Nerusi

Apabila kain sudah dicorek 'dipola' atau sudah ada ngengrengan, langkah selanjutnya adalah nerusi yaitu ngiseni atau mengisi gambar yang telah dipola. Ngiseni termasuk nyeceg, yaitu mengisi gambar yang telah dipola dengan titik-titik. Apabila sudah diiseni dengan ceceg-ceceg, selanjutnya diteruskan dengan gambar yang tidak begitu rumit, misalnya lengkung-lengkung atau ler-ler 'garis-garis'.

\subsection{Nembok}

Apabila pola sudah diisi dengan ceceg-ceceg, ler-ler atau lengkung-lengkung, proses selanjutnya adalah nemboki 'menutup bagian yang dikehendaki tetap putih dengan lilin'. Bagian yang ditutup yaitu selain bagian yang sudah digambar dengan ceceg-ceceg atau ler-ler.

Setelah ditembok kain kemudian dileleh yaitu digelar di tempat yang panas untuk melelehkan malam 'lilin' yang tidak bagus atau kotoran-kotoran lelehan malam 'lilin' pada kain. Proses ini tidak boleh terlalu lama karena lilin akan meleleh mengotori kain. Penjemuran dilakukan agar malam 'lilin menempel kuat pada kain, selanjutnya kain diwedel. ${ }^{11}$

\subsection{Mêdêl}

\footnotetext{
10 Departemen Perindustrian Rakyat, Batik, 1960, hal. 8

11 @ Kajawèn: angka 5, Sêlasa, Paing, 26 Dulkangidah, Jimawal 1869. 17 Januwari 1939, taun XIV, hal.12
} 
Kain putih yang telah selesai dingengreng dan ditembok kemudian dimasukkan ke dalam bak yang telah diisi dengan larutan indigo-pasta atau nila yang dicampur dengan kapur dan tunjung, dimaksudkan supaya bagian kain yang tidak tertutup gambaran lilin menjadi berwarna biru tua. Tingkat pekerjaan ini disebut dengan medel atau nyelup. 12

\subsection{Ngêrok}

Pekerjaan selanjutnya ngerok yaitu melepaskan lilin klowongan. Menghilangkan gambaran lilin rengrengan ini memakai kaleng yang ditajamkan bagian sebelahnya dan dikerjakan dengan tangan saja. Pekerjaan ini disebut dengan ngerok atau ngerik, dan dimaksudkan agar bekasnya nanti dapat diberi warna soga (coklat).

\subsection{Mbironi}

Mbironi yaitu menutup warna biru yang diinginkan tetap biru. Kain yang telah selesai dikerok, kemudian pada bagian-bagian corak yang dikehendaki tetap berwarna biru tua perlu ditutup dengan lilin. Pekerjaan ini biasa dilakukan untuk batik tulis.

\subsection{Nyoga}

Kain yang telah selesai dibironi kemudian secara satu persatu dimasukkan dalam larutan soda atau ekstrak soga agar mendapatkan warna coklat pada bagian bekas kerokan. Kain selanjutnya dibironi, yaitu menutup latar kain yang mula-mula berwarna biru dengan maksud apabila diwedel atau dicelup maka akan muncul warna lainnya, misalnya hitam, coklat dan sebagainya. Demikian pula ceceg, apabila menginginkan tembokan dengan warna lain harus dibironi atau ditutup dengan lilin agar memperoleh warna yang berbeda. Apabila tembokan ada yang thethel 'mengelupas' maka segera ditutup dengan lilin lagi agar warna merata tidak belang. 13

Nyoga kain termasuk ke dalam proses nyelup. Nyelup adalah proses pemberian warna pada kain batik. Proses ini bisa terjadi beberapa kali tergantung pada warna yang diinginkan. Apabila menginginkan tiga warna dalam satu kain, maka dilakukan tiga kali proses pencelupan.

Nyelup kain ada yang dimasukkan ke dalam larutan soda atau ekstrak soga agar mendapatkan warna coklat. Proses pencelupan agar mendapatkan warna coklat ini dinamakan nyoga.

\footnotetext{
12 Departemen Perindustrian Rakyat, Batik, 1960, hal 8-9.

13 @ Kajawèn: angka 9, Sla, Lê, 10 Bêsar, Jimawal 1869. 31 Januwari 1939, taun XIV, hal. 18
} 


\subsection{Mbabar}

Mbabar kain disebut juga dengan istilah nglorod yaitu menghilangkan semua lilin yang menempel pada kain dengan cara memasukkan kain ke dalam kenceng besar yang berisi air panas. Kain selesai dilorod dan bersih dari segala lilin yang menempel, selanjutnya kain dimasukkan ke dalam air bersih dan dicuci. Setelah itu dicuci kembali dengan menggunakan campuran air tawas. Selanjutnya dicuci lagi dengan air bersih dan kain sudah siap menjadi babaran. Kain babaran yang masih basah ini selanjutnya dijemur dan kain sudah siap untuk digunakan sebagai bahan sandang. ${ }^{14}$ Nglorod ialah tingkatan pekerjaan yang terakhir yaitu kain-kain yang telah selesai disoga dan warnanya cukup tua kemudian dimasukkan ke dalam kenceng besar berisi air panas.

3. Motif Batik

Secara umum, motif-motif kain batik baik di Laweyan maupun di daerah lain ada bermacam-macam, yaitu: Unthuk banyu, Udan riris, Nagasasi, Nagasruni, Cindhe wilis, Cakar ayam, Cakar rengganis, Cuwiri, Cepaka mulya, Ceplok sinupit, Rujaksenthe, Koci, Krenis, Krambil sacukil, Kuwung sari, Sawat, Perangrusak, 15 Modang, Cumengkiran,16 Udan liris, Tumpal,17 Kembangan dengan warna Udaraga,18 Bango tulak, 19 Lenga teleng, 20 Daragem tenun, 21 Cumengkirang dengan hiasan lunglungan atau bunga-bunga. Sawat katandhan dengan motif sayap burung, Kepetan, Kapidhondhong, Kembang asêm, Kembang asem klawer, Kembang kenthang, Kembang kapas, Kembang dlima, Kembang lateng, Kembang manggar, Daragelar. Plangen dengan motif parang-parangan serta semen-semenan misalnya Semen latar putih, Sridenta, Sriwadari, Worawari rumpuk, Lung adas, Lung kestlop, Lungtaman, Lungsrimpi, Lungmawar, Pandelegan, Parikesit, Parangrusak kalithik, Parangrusak kagok, Purbayasa, Purbangkara, Parangrusak gendreh, Parangrusak @ Kajawèn: angka 93, Sla, Wa, 19 Sawal, Dal 1871. 19 Nopèmbêr 1940, taun XV, Kawruh Bathik WarniWarni. hal. 1312.

15 Istilah yang umum dipakai sekarang adalah Parang rusak.

$16 \quad$ Istilah yang umum dipakai sekarang Cemukirang, Semukirang

17 Bagian tengah berwarna putih, bagian pinggir batik

18 Bagian tengah berwarna merah, bagian pinggir seret ijo kuning 'sedikit hijau kekuningan' hitam pinggir putih)

20 Bagian tengah berwarna putih, bagian pinggir berwarna hitam. 
barong, Parangkusuma, Parangwesthi, Parangganda, Pakuningrat, Paksi anjalipatna, Peksi renggapuspita, Peksi kresna, Jendral nginum, Jlengut, Jlengut grudha, Jayaresmi, Jayakirana, Jayakusuma, Jonggrong, Jamblang. ${ }^{22}$

Beberapa keterangan lengkap mengenai beberapa motif tersebut di atas adalah sebagai berikut.

\subsection{Udan-riris 23}

Udan-riris adalah nama motif jarit dengan bentuk garis-garis miring, umumnya diucapkan dengan istilah dan-riris, atau udan-liris. Motif ini mempunyai latar 'warna dasar' hitam, sedangkan jika dibuat dengan latar warna putih, disebut dengan istilah rujak senthe. Motif ini memiliki ciri khas sogan maupun celepan atau wedelan serba tua, sehingga terlihat ngengreng 'berwibawa'. Motif Udan riris termasuk motif yang tidak boleh dipakai oleh masyarakat umum, biasanya hanya dipakai oleh kalangan bangsawan. Kain ini sangat luwes 'pantas' dipakai, baik wanita maupun pria.

Motif ini walaupun meniru atau menyerupai bentuk tertentu, tetapi tidak diujudkan dengan jelas, misalnya motif Udan riris dengan gambar rusa, maka ujud rusa tersebut tidak diujudkan dengan jelas, sehingga kalau dilihat sama sekali tidak menyerupai gambar rusa. Selain itu motif Udan riris mempunyai maksud jawah ingkang damel sengsem 'hujan yang menyebabkan kasmaran'.

Garis-garis pada kain jarit motif udan-riris dibuat dengan menggunakan garisan dengan panjang lebar yang tidak sama, tetapi ajeg. Misalnya dimulai dengan seratan 'corak' parang rusak, diteruskan dengan motif yang lain dan diakhiri motif parang rusak lagi, demikian seterusnya. Tetapi ada juga kain motif udan riris dengan luas garis-garis sama dan diberi bathikan 'pola motif batik' yang berbeda. Bahkan para ahli batik ada yang menyebutkan bahwa bathikan pada udan riris dalam satu kain, tidak ada yang sama. Sedangkan dalam udan riris sistem cap, bathikannya lebih sederhana (Kajawen, 1937: 156).

3.2 Parang-rusak 24

$22 @$ @irapustaka, Layang Bauwarna Jllid I-IV, 1828.

23 Kajawèn: angka 80, Rê, Wa, ${ }^{23} 1$ Ruwah Ehe 1868. 6 Oktobêr 1937, taun XII, Bab Nyerat (ambathik), hal. 156.

24 @ Kajawèn: angka 76, Rê, Kli, 17 Rêjêp Ehe 1868. 22 Sèptèmbêr 1937, taun XII, Bab Nyerat (ambathik), hal. 146. 
Semua kain batik motif parangrusak memiliki mlinjon yakni guratan gambar berbentuk persegi miring bergandengan. Sedang berdasarkan besar kecilnya bathikan serta perubahan bentuk, menyebabkan perubahan nama kain, misalnya jika bathikan lebih besar disebut parangrusak barong (Kajawen, 1937: 146).

Sinjang parangrusak disebut sinjang garis miring berupa garis-garis miring pada kain. Di Jawa kain ini menjadi larangan dan hanya boleh dipakai oleh kalangan bangsawan saja. Menurut cerita, yang menjadi larangan bukan karena motif-motif garis miringnya tetapi karena adanya mlinjon. Padahal sebenarnya, motif ini termasuk motif yang sangat bagus dan banyak menjadi pilihan, karena jika dipakai maka pemakainya akan terlihat bagus, jelas dan cerah warnanya. 25

Menurut Proffessor Raufaer bahwa motif Parangrusak meniru bentuk burung Albatras. Di tanah Papua dan pulau Moloko, ada sejenis burung yang hidup dan tinggal di rawa-rawa. Nama burung tersebut adalah Albatras dan dapat terbang seperti burung Mliwis. Burung tersebut sangat indah, sehingga bentuknya ditiru untuk hiasan rumah atau senjata oleh orang-orang di pulau tersebut. Diceritakan bahwa Raden Bondan Kajawan, putra Prabu Brawijaya di Majapahit, berkeinginan membuat motif kain batik dengan meniru bentuk bulu burung Albatras, yang selanjutnya dikenal dengan nama motif Parangrusak. Rakyat jelata dilarang memakai motif parangrusak ini. ${ }^{26}$

Berdasarkan kisah dan kabar yang beredar di masyarakat, penyebutan nama kain parangrusak memiliki bermacam-macam alasan, yakni: 1. mengambil dari parang putung 'pedang patah', 2. parangcuri (pedang yang rusak) 3. meniru dari wujud sungu menjangan 'tanduk rusa'. 4. bentuk keris, 5. bentuk kudhuping tunjung 'kuncup daun tunjung', sebagai simbol hidup baru, 6. meniru dari ukiran pakaian Raden Panji setelah dipakai untuk membunuh Dewi Angreni, 7. meniru wujud parang 'karang' yang rusak karena terkena tetesan air yang berasal dari rembesan air pada karang terjal yang dilihat oleh Sultan Agung. Yakni kisah saat Sultan Agung mandi di tepi laut selatan, melalui jurang sepanjang tepi laut. Di tempat itu banyak pemandangan yang membuat nyaman dalam hati. Saat melihat ke selatan terlihat lautan yang luas tanpa tepi, pertemuan gelombang menimbulkan suara menggelegar, berkumandang sampai di langit. Pecahnya gelombang tersebar seperti awun-awun. Parangcuri 'karang terjal' di pinggir laut

$25 @$ Lampiran Kajawèn nomêr 26, 29 Juni 1938 taun III, Jagading Wanita, hal. 139 
merembes karena bersatunya air yang menetes jatuh pada karang yang terjal, sehingga terlihat membekaskan semacam garis panjang.

Keadaan tersebut menumbuhkan perasaan tentram, sehingga sesampainya di kerajaan memerintahkan untuk membatik kain dengan motif menyerupai karang terjal yang rusak wujudnya. Motif batik itu dikenal dengan motif batik parang rusak. Pada zaman dahulu, pembuatan batik motif parang rusak harus didahului dengan pemasangan sesaji, sebab merupakan kain larangan, yang hanya boleh dipakai oleh kalangan bangsawan, khususnya raja. Selain motif parangrusak, nama-nama motif kain banyak yang mengambil dari kisah-kisah masa lalu, misalnya motif semen rama diambil dari cerita Prabu Rama. Semen angreni mengambil dari cerita Dewi Angreni. 27

\subsection{Kawung Robyong 28}

Kawung robyong adalah percampuran antara kawung warna hitam dan putih, percampuran antara kawung dengan sogan berisi sawut cêcêk. Kain yang demikian jika pembatikannya tepat akan menghasilkan kain dengan wujud peni sebab perpaduan warna terlihat jelas. Jika warna hitam diwedel 'dicelup' sebentar akan berubah menjadi warna biru muda.

Robyong maksudnya warna rembyak-rembyak. Jika dilihat sekilas tidak beraturan tatanannya, namun jika diperhatikan lebih lanjut akan terlihat bentuk baku yang muncul dari latar berwarna putih, hitam dan sogan.

Kain kawung robyong termasuk jenis bathikan baru yang muncul setelah adanya motif kawung berlatar warna hitam. Membatik kain motif kawung harus berhati-hati sebab jika tidak berhati-hati akan menghasilkan kain dengan motif yang dhumpyuk 'bertumpuk'. Kain ini umumnya dipakai oleh kaum muda karena motifnya memunculkan perasaan berag 'lincah, dinamis' sehingga kurang pas apabila dipakai oleh orang tua.

\subsection{Gringsing 29}

Sinjang gringsing adalah kain dengan latar berwarna putih, sedangkan bathikan boleh bebas. Gringsing ini bermacam-macam, misalnya: gringsing ringgit, gringsing klungsu tuwin gringsing sisik.

@ Wirapustaka, Layang Bauwarna Jllid II, 1828, hal 1354; Lampiran Kajawèn nomêr 26, 29 Juni 1938 taun III, Jagading Wanita, hal. 139.

Kajawèn: angka 10/11, Stu, ${ }^{28}$ Lê, 5 Bêsar Ehe 1868. 5 Pebruwari 1938, taun XIII, Kawung Robyong, hal. 20. Kajawèn: angka 80, Rê, Pn, 10 Ruwah, Jimawal 1869. 5 Oktobêr 1938, taun XIII, Sinjang Gringsing, hal. 155. 
Kain dengan motif gringsing sisik mengambil model sisik ikan, bathikannya bertingkat-tingkat, bertumpangan seperti sisik ikan. Jika pengerjaannya tepat, maka warna putihnya akan terlihat sumeblak 'terang dan jelas'. Hal baku dalam pembuatan kain bermotif gringsing sisik adalah mengutamakan putihnya gringsing bukan gumêbyaring sogan 'terangnya sogan'.

Sinjang gringsing pantas dipakai oleh wanita, dan cocok dipadukan dengan kebaya apa saja. Dipakai oleh orang dengan warna kulit gelap terlihat wijang, dipakai oleh wanita berkulit terang terlihat ngalela. Di dalam cerita, kain ini pernah dipakai oleh Rara Mendut yang terkenal sangat cantik, dipadukan dengan kain kemben berwarna jingga. Dengan memakai kain dan kemben tersebut, Rara Mendut yang berkulit langsat diumpamakan wajahnya ngegla padhang seperti bulan purnama.

3.5 Slobog 30

Sinjang Slobog termasuk kain dengan batikan kuno. Ada yang disebut slobog cukèn, slobog jôntra serta salobog asmaradana. Slobog cuken, misalnya, mengambil model papan permainan dham dengan cêcêg. Kadang ceceg diganti dengan cacah gori atau motif yang tidak beraturan menyerupai potongan-potongan gori 'nangka muda' yang hendak disayur. Sinjang slobog lebih pantas dipakai oleh orang yang sudah tua.

Menurut cerita, ketika Gusti Kangjêng Ratu Kancana (Kangjêng Ratu Bêruk) ing Surakarta masih menjadi manggung, tidur di dalêm Prabasuyasa. Tengah malam beliau mendapatkan wahyu sedang memakai sinjang Slobog. Oleh karenanya beliau memerintahkan kepada putra wayah 'anak cucu' agar jangan mengabaikan sinjang Slobog.

Demikian juga menurut cerita dari para sesepuh pada masa pemerintahan Ingkang Sinuhun kaping sanga 'Pakubuwana IX'. Beliau seringkali dijumpai dengan memakai nyamping slobog 'kain slobog' dengan paningsêt mori pêthak dan èpèk cêmêng. Pada saat memakai pakaian seperti tersebut di atas, beliau dijuluki baris pêndhêm. 
3.6 Kawung 31

Diantara motif-motif kain lain, motif kawung lebih banyak dikenal dan disukai. Pada umumnya semua orang mengenal kain dengan motif kawung sebab bentuk dan kenampakannya bagus, baik dilihat dari dekat maupun dari kejauhan. Untuk kain motif kawung, bathikan kain sebaiknya berbentuk sedang (ideal), tidak terlalu besar atau terlalu kecil.

Jejer 'pola dominan yang tergambar dalam kain' bermotif kawung sama, bedanya dalam hal besarnya isen-isen, besar, kecil, bulat atau persegi. Begitu juga dalam hal tembokan 'bagian yang tidak bergambar' maupun mlinjon. Perbedaan tersebut menyebabkan adanya nama sinjang kawung yang berbeda-beda, misalnya kawung picis, kawung sari, kawung garèng. Hal baku yang harus diketahui dalam pengerjaan kain bermotif kawung, bahwa seluruh kain dibatik penuh dengan pola kawung. Tetapi banyak juga bentuk-bentuk modifikasi dengan penambahan pola selaan berupa buntal, bokèt, êlar dan lain-lain. Pola selaan tersebut disebut dengan istilah rêrênggan yang menambah keasrian kain bermotif kawung.

Sinjang kawung ini termasuk sinjang luwesan, serba pantas dipakai oleh orang dengan warna kulit gelap maupun terang. Untuk wanita sebaiknya memilih motif kawung dengan pola gambar yang sedang. Di Kraton Yogyakarta, sinjang kawung, seperti halnya sinjang parangrusak menjadi kain larangan artinya tidak boleh dipakai oleh sembarang orang, karena biasanya dipakai oleh raja, keluarga raja atau orang dalam 'kalangan bangsawan'.

\subsection{Sidamukti 32}

Sinjang Sidamukti termasuk sinjang latar pethak dengan pola gambar yang rumit. Untuk orang-orang jaman dahulu, kain dengan motif ini merupakan kain pilihan sehubungan dengan namanya yang memiliki maksud yang baik. Jika melihat dari pola gambar baku, nama Sidamukti diambil dari bentuk bathikan yang malang megung 'tidak teratur tatanannya' menyerupai bentuk tumbuhan, sedangkan bathikan yang lain hanya berlaku sebagai rerenggan 'hiasan pelengkap'.

Disebut sinjang latar pêthak sebab warna bakunya hanya berasal dari warna latar kain, dan di sela-sela hiasan berwarna putih dengan isen-isen warna putih. Isen-

$31 @$ @ampiran Kajawèn: nomêr 1 taun III, Jagading Wanita, hal.4

$32 @$ Lampiran Kajawèn nomêr 26, 29 Juni 1938 taun III, Jagading Wanita, hal. 103 
isen bermacam-macam bentuknya mialnya ada yang dibentuk unthêr, bledhak, atau tembokan lugu. Meskipun biasanya, yang disebut sinjang latar pethak mempunyai isenisen berbentuk unther.

Sinjang Sidamukti tergolong sinjang luwêsan baik yang dikerjakan dengan sogan mramong'menyala' maupun sogan kêlêm 'gelap' sama baiknya. Kain ini paling cocok dipadukan dengan atasan berwarna dasar gelap, dengan hiasan bunga-bunga kecil yang jelas.

\section{Pemakaian}

Pada masa lalu kain motif batik hanya dipakai oleh kalangan tertentu, misalnya raja dan keluarganya. Sampai saat ini pun, masih ada kain batik dengan jenis tertentu yang disirik atau dilarang untuk dipakai oleh kalangan kebanyakan karena merupakan pakaian kebesaran raja, sebab diyakini akan menimbulkan walat.

Biasanya pakaian yang dipakai oleh raja berbeda dengan pakaian yang dipakai oleh bawahan, putra, atau sentana. Dalam hal pemakaian kampuh, misalnya, 1. Kampuh yang dipakai oleh Sinuhun Kangjêng Susuhunan berasal dari bahan sutra atau kain non sutra sesuai selera, batik plangèn 'motif warna-warni, pelangi', parang-parangan, sêmèn-sêmenan sesuai selera; 2. Kampuh yang dipakai oleh Kangjêng Gusti Pangeran Adipati Anom, id. kampuhan kasatriyan, ngumbar kunca, ngagêm pasikon, panunggul mathak, ngêmbang gundha ngagêm nyamat; 3. kampuh yang dipakai oleh para pangeran, putra, santana dalêm, serta riya dhuwur dengan kain batik bermotif parangparangan atau sêmèn-sêmenan dengan lar urip; 4. kampuh yang dipakai oleh kangjêng radèn adipati, serta wadana, kaliwon adalah kain batik sêmèn dengan latar warna putih, lar urip model kampuh tumênggungan. 33

Hal itu terjadi karena aturan berpakaian pada masa kerajaan bergantung pada kebijakan raja. Seringkali, raja menentukan pakaian apa yang harus dipakai oleh para bawahannya pada hari-hari tertentu. Misalnya, Pada 16 Sapar Ehe $1828^{34}$ raja Surakarta menentukan dodot yang harus dipakai oleh para abdi dalêm wadana, kaliwon, panèwu, mantri, lurah, bêkêl, jajar, rôngga, dêmang, panatus, panèkêt, panglawe pada hari-hari besar, seperti uraian berikut. (a) Wadana kaliwon memakai dodot berupa kain batik sêmèn latar putih dengan lar urip; (b) Panèwu mantri memakai dodot berupa kain

33 Wirapustaka, Layang Bauwarna jilid 2, 1828, hal.249.

34 Rabu Pon, 6 Juli 1898 A.D. 
batik sêmèn latar irêng dengan lar mati; (c) Panèwu mantri urdênas memakai dodot berupa kain batik motif pandêlêgan; (d) Panèwu mantri bêkêl jajar gandhèk memakai dodot berupa kain rèjèng; (e) Dêmang, panatus, panèkêt, panglawe niyaga, memakai dodot berupa kain slobog; (f) Mantri kanoman memakai dodot berupa kain kumitir; (g) Mantri sangkraknyana memakai dodot berupa kain modang; (h) Mantri saragêni memakai dodot berupa kain padhas gêmpal; (i) Jajar priyantaka memakai dodot berupa kain lurik bêrkutut manggung, mantrinya memakai seperti lêtl. b; (j) Lurah badhut memakai dodot berupa kain sindur; (k) Panèwu mantri rôngga pulisi memakai dodot berupa kain wora-wari rumpuk; (1) Ngulama memakai dodot berupa kain ayam pugêr; (m) Kadipatèn anom memakai dodot berupa kain jambêlang; dan (n) Kapatihan memakai dodot berupa kain krambil sacukil. 35

\section{KESIMPULAN DAN SARAN}

Laweyan adalah kampung batik di kota Surakarta. Kampung ini memiliki keunikan-keunikan yang perlu dikuak sebagai khazanah budaya. Keunikan tersebut di antaranya dapat dilihat dari tradisi masyarakat Laweyan yang bermata pencaharian dari perdagangan dan pembuatan kain batik.

Proses pembuatan satu kain batik memerlukan waktu yang panjang, yaitu mulai nggirah 'mencuci mori', ngethel, nyorek 'memberi gambaran pola pada kain', ngiseni, nembok, nyelup sampai mbabar atau nglorod lilin pada kain.

Pada masa lalu kain motif batik hanya dipakai oleh kalangan tertentu, misalnya raja dan keluarganya. Seiring dengan perkembangan jaman, kain batik telah dipakai secara kontemporer oleh banyak kalangan. Saat ini, meskipun batik dipakai sebagai pakaian resmi nasional, namun banyak juga di antara para ahli tata busana yang memodifikasi kain batik menjadi pakaian sehari-hari. Namun demikian, tetap ada pilihan penggunaan kain batik dengan motif tertentu, misalnya kain batik motif sidamukti biasa dipakai pada acara pernikahan.

Berdasarkan etika berpakaian, kain batik dengan latar warna hitam lebih cocok dipakai oleh orang tua, sedangkan kaum muda lebih cocok untuk memakai kain batik dengan latar warna putih. Namun demikian, hal itu kembali lagi pada si pemakai dan menyesuaikan dengan selera masing-masing pemakai. 
Kawruh: Journal of Language Education, Literature, and Local Culture

Volume 1, Nomor 1, 2019

\section{DAFTAR PUSTAKA}

Departemen Perindustrian Rakyat. 1960. Buku Penuntun Batik. Yogyakarta: Institut Teknologi Dan Pendidikan.

Kamajaya. 1986. Serat Centhini Latin.

Padmasusastra. 1898. Layang Bauwarna. Koleksi Yayasan Sastra.

Majalah Kajawen 1931, Bale Pustaka. Koleksi Yayasan Sastra.

Majalah Kajawen 1937, Bale Pustaka. Koleksi Yayasan Sastra.

Majalah Kajawen 1938, Bale Pustaka. Koleksi Yayasan Sastra.

Majalah Kajawen 1939, Bale Pustaka. Koleksi Yayasan Sastra.

Majalah Kajawen 1940, Bale Pustaka. Koleksi Yayasan Sastra.

Majalah Kajawen 1941, Bale Pustaka. Koleksi Yayasan Sastra. 